\title{
When should I stop anticoagulation for atrial fibrillation?
}

Tam a practising community 1 family physician with 199 patients over the age of 64 years. Eleven $(5.5 \%)$ of them are taking warfarin for atrial fibrillation. Anticoagulation reduces the relative risk of stroke by about $70 \%$ over 5 years; ${ }^{1}$ however, patients are at risk of bleeding. Although the risk of a serious life-threatening or fatal bleed is about $5 \%$ over 5 years for most patients, it is $17 \%$ over 5 years for patients over the age of 80 .

Six of my patients using warfarin for atrial fibrillation are over the age of 80 . I calculated their 5year risk of having a stroke (using the Framingham calculator, www.statcoder.com) to be $18 \%$, $19 \%, 21 \%, 31 \%, 41 \%$ and $55 \%$ respectively. I determined that, if a patient has a risk of stroke of $24 \%$ over 5 years, then that risk would fall by $70 \%$ with warfarin, to $7.2 \%$. The net improvement or absolute risk reduction would be $16.8 \%$. If the risk of a serious bleed from warfarin therapy is $17 \%$ over 5 years, then all patients with a stroke risk of $24 \%$ or less would have the benefit of warfarin therapy counterbalanced by a risk of a serious side effect. (Note that by using general principles of risk equivalence, ${ }^{3}$ this determination can also be calculated as risk of adverse event : relative risk benefit - in this case $17 \% \div 0.7=24 \%$.) I reviewed the treatment of my 6 patients, and it appeared to me that 3 of them should continue to take warfarin and 3 should consider switching to ASA.

I acknowledge limitations to my approach. The estimates of risk of anticoagulation are limited, since they are derived from a single trial (and not a metaanalysis of trials in several populations) and have wide confidence intervals surrounding them. In addition, risks (of the condition and the treatment) are patient specific and depend on factors not included in the calculations (e.g., concurrent illnesses and medication use, and whether the patient agrees with my assumption that a serious outcome such as stroke might have the same impact on one's life as a severe bleed). Still, I wonder: Is my approach to risk equivalence ready for prime time?
Michelle Greiver

Department of Family and

Community Medicine

University of Toronto

Toronto, Ont.

\section{References}

1. Segal JB, McNamara RL, Miller MR, Powe NR, Goodman SN, Robinson $\mathrm{KA}$, et al. Anticoagulants or antiplatelet therapy for non-rheumatic atrial fibrillation and flutter. Cocbrane Database Syst Rev 2001;(1):CD001938.

2. Fihn SD, Callahan CM, Martin DC, McDonnell MB, Henikoff JG, White $\mathrm{RH}$, et al. The risk for and severity of bleeding complications in elderly patients treated with warfarin. Ann Intern Med 1996;124:970-9.

3. Barratt A, Wyer PC, Hatala R, McGinn T, Dans AT, Keitz S, et al. Tips for learners of evidence-based medicine: 1 . Relative risk reduction, absolute risk reduction and number needed to treat. CMAF 2004;171(4):353-8.

\section{What's your opinion?}

We invite you to submit your ideas about the author's approach to risk equivalence by sending an eLetter response to this article at www.cmaj.ca. The best comments will be summarized in an upcoming issue and a small prize awarded.

Do you have a case that you can't diagnose? Send a description of it to the attention of Dr. Wooltorton at eric.wooltorton@cma.ca.

\section{Earlier clinical conundrum resolved: a diagnosis with teeth}

W e received a number of eletters (available with the original article ${ }^{1}$ at www.cmaj.ca) suggesting possible diagnoses in the case of a man who was noted at autopsy to have several unusual structures near his pancreas. Many different pathologies were proposed, including a neuroendocrine neoplasm, cystadenoma, inflammatory pseudotumour, scle- rosing mesenteritis (panniculitis), thymus remnant, tuberculoma, hamartoma, and dermoid or hydatid cysts due to foreign body reactions possibly from a remote gun-shot injury or bomb splinter.

The most common, and perhaps best argued, diagnosis was a lymphoepithelial cyst of the pancreas. Such a lesion, which is a frequent incidental finding on abdominal CT scans, is benign and occurs more commonly in men than in women. Histologically similar lesions have been found in the parotid and thyroid glands, the neck (brachial cleft cysts), the thymus and the lungs. This clinical entity was described nearly 160 years ago by a dentist who felt that the lesion's characteristic luminal pearls very closely resembled teeth. ${ }^{2}$

The diagnosis of lymphoepithelial cyst of the pancreas reached us independently on the same day from Dr. Nick G.

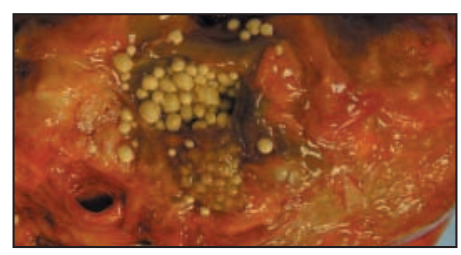

van der Westhuizen and Dr. Heike Varnholt (who also pointed us to the first case report $\left.^{2}\right)$. To both we offer a small but nifty prize, a CMA7 combination pedometer and radio.

\section{Eric Wooltorton}

CMAF

\section{References}

1. Meneghetti V, Lee C, Perry TL, Andrews $G$. An unusual structure near the porta hepatis: What's your diagnosis? CMAf 2004;171(9):1048-9.

2. Bond TE Jr. A practical treatise on dental medicine. Philadelphia: Lindsay \& Blakiston; 1848. 